\title{
VERY HIGH ELECTRON TEMPERATURES IN THE DAYTIME F REGION AT SONDRESTROM
}

\author{
Wlodek Kofman' ${ }^{1}$ and Vincent B. Wickwar ${ }^{2}$ \\ ICentre d'Études des Phénomènes Aléatoires et Géophysiques, St. Martin d'Hères, France \\ ${ }^{2}$ Radio Physics Laboratory, SRI International
}

\begin{abstract}
Sondrestrom observations show that a characteristic F-region signature of the interaction between the magnetosphere and ionosphere is a narrow band of elevated electron temperatures. Its location is associated with the ion convection reversal in the morning and evening convection cells. Typically, near $500 \mathrm{~km}$ altitude, the temperature is 3500 to $4000 \mathrm{~K}$. However, on 24 April 1983, a geomagnetically very active day with $\mathrm{Kp}$ values of 6-during the period of interest, the electron temperature reached $6000 \mathrm{~K}$ in the afternoon convection reversal. The ion velocities were between 1 and $2 \mathrm{~km} / \mathrm{s}$ on both sides of the reversal. There was considerable soft particle precipitation and a large downward heat flux of $0.3 \mathrm{erg} / \mathrm{cm}^{2}-\mathrm{s}$ at $450 \mathrm{~km}$. These high temperature electrons then transferred $0.5 \mathrm{erg} / \mathrm{cm}^{2}-\mathrm{s}$ to ions and neutrals between 175 and $550 \mathrm{~km}$, which represents a very sizeable perturbation to the thermosphere.
\end{abstract}

\section{Introduction}

An electron temperature of $6000 \mathrm{~K}$ at $500 \mathrm{~km}$ altitude is very unusual. Typical daytime temperatures, with solar input alone, are 2000 to $3500 \mathrm{~K}$ [Schunk and Nagy, 1978]. Typical daytime temperatures at Sondrestrom, when there is soft particle precipitation, are 3500 to $4000 \mathrm{~K}$ [Wickwar and Kofman, 1984]. Similar temperatures have also been observed at higher altitudes, in a region identified as the cusp, from ISIS 2 [Titheridge, 1976] and DE 2 [Brace et al., 1982]. The very high $6000 \mathrm{~K}$ temperature has been observed near $800 \mathrm{~km}$ in a SAR arc [Kozyra et al., 1982], near $500 \mathrm{~km}$ in a type A red aurora at Chatanika on 5 March 1981, and near $400 \mathrm{~km}$ in the August 1972 storm [Fontheim et al., 1978].

In this paper we examine the conditions under which this unusual event occurred at Sondrestrom, the associated heat flux into the electron gas, and the energy transferred from the hot electrons to the other atmospheric constituents. But first, we describe the analysis procedure.

\section{Method}

The data were acquired at Sondrestrom in a general survey mode [Wickwar et al., 1984]. Many of the analysis procedures used are also described in Wickwar et al. [1984] and the references therein. However, they have been extended recently in ways that we will briefly summarize.

The derivation of the heat flux from radar data is not a

Copyright 1984 by the American Geophysical Union.

Paper number 4L6264.

0094-8276/84/004L-6264\$03.00 standard procedure. In order to gain greater confidence in the results, we derive the heat flux in two ways. First we find the heat flux from the electron thermal conductivity and electron temperature gradient [Schunk and Nagy, 1978, and references therein]. This method applies at all altitudes, but requires evaluation of the temperature gradient along the magnetic field line. Second we assume that the heat flux is constant along the magnetic field and that the thermal conductivity for a fully ionized gas applies. We then integrate the heat conduction equation, solving for the constant heat flux in terms of the electron temperature at two altitudes [Schunk, 1983]. This method is simpler because it does not require the gradient, but is limited to the region above the F-region density peak.

To find the electron temperature gradient needed above, we make a least squares fit of spline functions to the electron temperature profile. The same type of fitting is also performed on the ion temperature profile. In addition to finding the gradient, the resultant smoothed electron and ion temperatures can be combined with the ion energy equation, in a manner similar to that of Bauer et al. [1970], to derive the exospheric temperature $T_{\infty}$. A good value for $T_{\infty}$ is obtained, provided the ion temperature is not increased by Joule heating, i.e., when ion velocities are small. We use this exospheric temperature as an input to the Jacchia [1971] model atmosphere to obtain neutral densities and temperatures. The three temperature profiles, electron densities, and neutral densities are then combined to calculate the energy loss rate from electrons to ions and to neutrals produced by collisions [Schunk and Nagy, 1978]. This parameter is useful because it gives the net energy deposited in the electron gas from all sources, local and nonlocal. Because most of this energy is transferred to the neutrals, it also gives a lower bound to the energy deposited in the neutrals from these same sources.

\section{Observations and Discussion}

We examine elevated electron temperatures during two periods on 24 April 1983. The first is from 1346 to $1347 \mathrm{UT}$ when the radar was pointing along the magnetic field line. (1400 UT is approximately magnetic noon and $1500 \mathrm{UT}$ is approximately local noon.) This direction is convenient for determining the heat flux. The second period is near 1519 UT when the radar was scanning in elevation. This observing mode is convenient for determining latitudinal structure and for constructing the temperature profile along $B$ at the center of the heated region when that region is north or south of the radar.

In Figure 1 we show the two profiles of electron temperature. They are very similar. For comparison, we also show a 


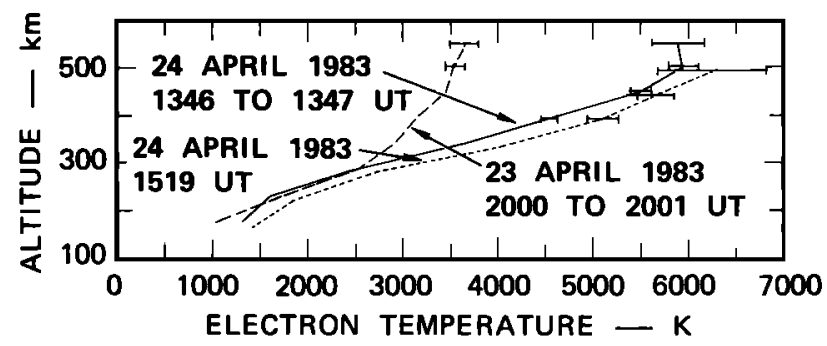

Fig. 1. Profiles of electron temperature. One has a typical enhancement, two have unusually large enhancements.

more typical profile, from 2000 to 2001 UT on 23 April 1983 when the region of maximum electron temperature was in the radar's magnetic zenith. Below $300 \mathrm{~km}$ the three curves are almost identical, but above that altitude the first two curves are greatly elevated.

The latitudinal structure of the heated region is obtained from the elevation scan between 1517 and 1522 UT. In
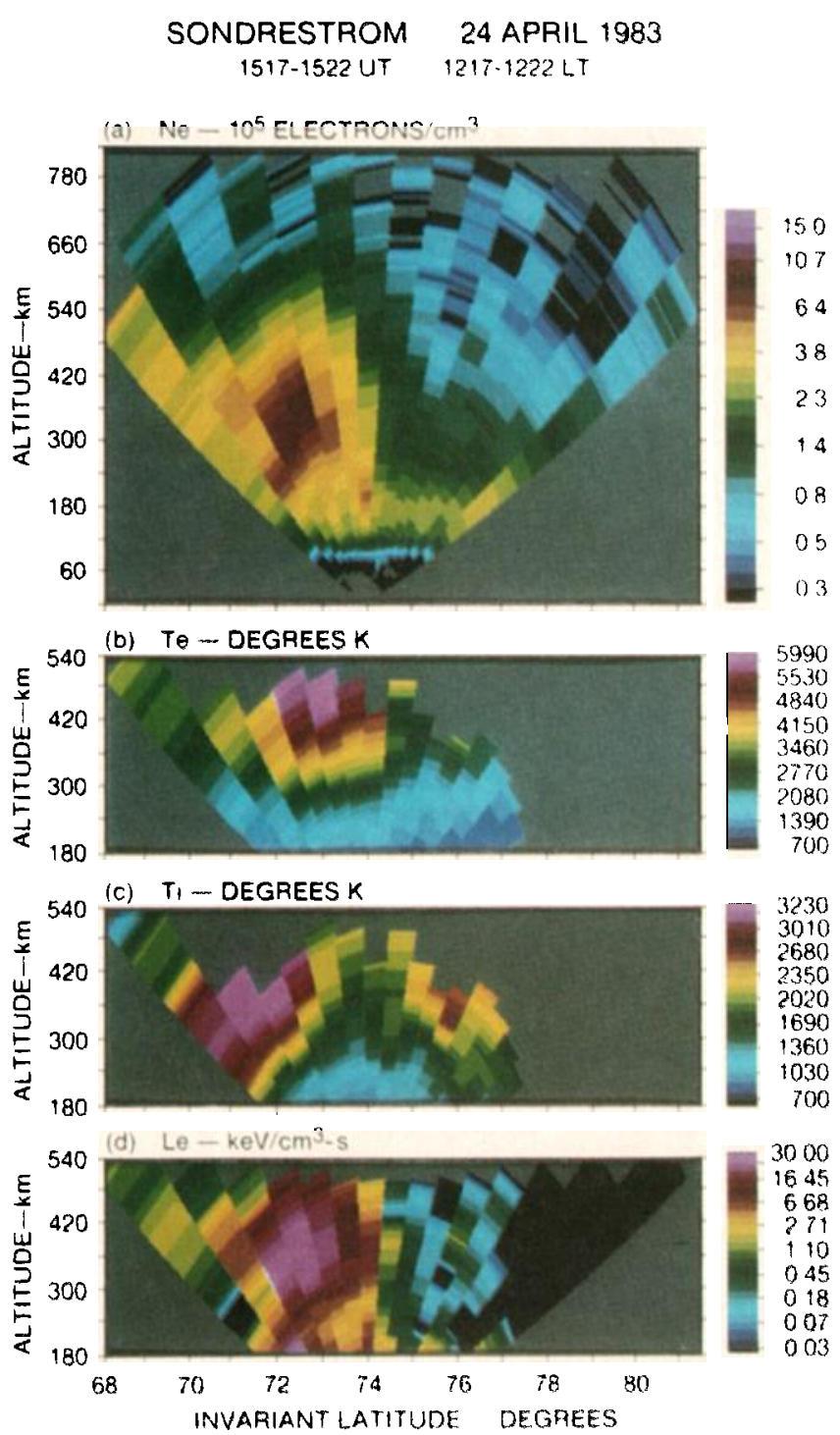

Fig. 2 Latitudinal variation of ionospheric parameters between 1517 and 1522 UT on 24 April 1983. (a) Ne, (b) Te, (c) $\mathrm{T}_{1}$, and (d) energy loss rate.

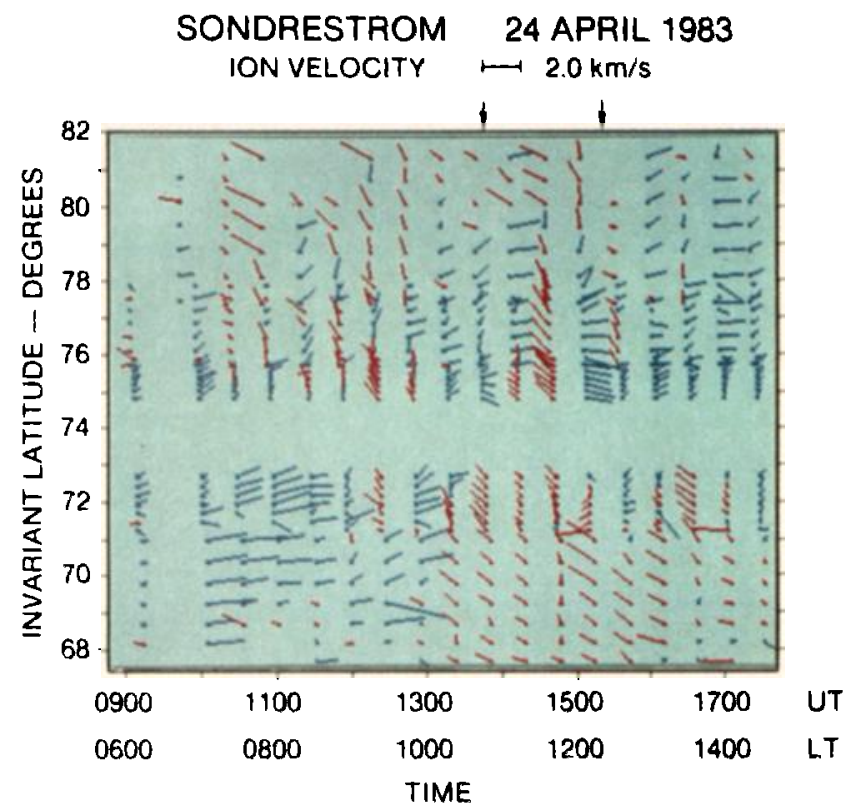

Fig. 3. Ion convection velocities for 24 April 1983. Vectors with an eastward component are in blue; those with a westward component are in red. The two arrows at the top indicate the measurements of greatest interest. The gap corresponds to the radar location.

Figures 2(a) through 2(d) we show electron density $\mathrm{Ne}$, electron temperature $\mathrm{Te}$, ion temperature $\mathrm{Ti}$, and calculated energy loss rate from electrons to ion and neutrals. Between 200 and $400 \mathrm{~km}$ altitude, the $\mathrm{Ne}$ plot shows a large enhancement, by almost a factor of three, between $71.5^{\circ}$ and $73.0^{\circ}$ invariant, i.e., over a distance of about $150 \mathrm{~km}$ Poleward of $74^{\circ}$, the F-region ionization falls off dramatically $\mathrm{Te}$ is elevated in the same invariant latitude region as $\mathrm{Ne}$. In contrast, $\mathrm{Ti}$ is greatly elevated between $70.5^{\circ}$ and $72.0^{\circ}$ and somewhat elevated between $75^{\circ}$ and $76^{\circ}$. Thus the center of the $\mathrm{Ne}$ and $\mathrm{Te}$ enhancements is well separated from the center of either Ti enhancement, although some overlap exists near $72^{\circ}$.

The fact that the $\mathrm{Ne}$ and $\mathrm{Te}$ enhancements coincide greatly suggests that they arise from a localized energy input that can ionize the neutrals as well as heat them, i.e., particle precipitation. Figure 2(d) shows a greatly enhanced electron energy loss rate that coincides with the $\mathrm{Ne}$ and $\mathrm{Te}$ enhancements. This coincidence further confirms the existence of a large localized energy input.

Before examining this energy input, we study where it occurs. The convection velocities are shown in Figure 3. On most days the radar observations show a slowly evolving convection pattern [e.g., 23 April 1983 shown in Wickwar and Kofman (1984)], but here, the temporal changes clearly occur faster than the time resolution of the experiment The gap in ion velocities corresponds to the radar latitude. The directions of the convection clearly show that at 1000 UT the radar is under the morning convection cell and at 1500 UT it is under the afternoon cell.

In Figure 3, arrows indicate the set of measurements that includes the elevated Te at $1346 \mathrm{UT}$ and the set that immediately precedes the elevation scan at 1517 UT In the first, 
the radar is under the convection reversal. The ion velocities north and south of the reversal are roughly $1 \mathrm{~km} / \mathrm{s}$ but are generally stronger on the equatorward side. In the second case, the elevated $\mathrm{Ti}$ in Figure 2(c) occur at the same location as the strongest ion velocities 9 min earlier, but not $18 \mathrm{~min}$ later. Therefore, the earlier convection measurement is the more representative of the conditions during the elevation scan. Again, this shows good agreement between the location of the reversal and the maxima in $\mathrm{Ne}$ and $\mathrm{Te}$. However, the ion velocities are almost double what they were in the first. In both cases the velocity pattern shows that the radar is under the afternoon convection cell. Thus, qualitatively, the conditions under which the very large Te enhancements occur are the same as for the more usual enhancements such as shown in Wickwar and Kofman [1984].

Following the arguments in Reiff et al. [1978], the sharp convection reversal observed in the afternoon is where we expect to find an upward Birkeland current and downward electron precipitation. This is consistent with the observed density increase.

The electron density increase and some of the electron heating will arise from these precipitating electrons, but the strong Te gradients suggest that a large downward heat flux also exists. In Figure 4 we show profiles of heat flux along $B$ for the unusual situation at 1346 UT on 24 April 1983 and for the more usual situation at 2000 UT on 23 April 1983. Also shown at high altitudes are the heat fluxes derived from integrating the heat conduction equation. The good agreement achieved with the two techniques under two very different conditions gives confidence to this derived parameter.

The heat flux into the ionosphere, determined at $450 \mathrm{~km}$, is an order of magnitude greater for the unusual situation than for the more usual one, $0.3 \mathrm{ergs} / \mathrm{cm}^{2}-\mathrm{s}$ compared with $0.03 \mathrm{ergs} / \mathrm{cm}^{2}-\mathrm{s}$. Below $280 \mathrm{~km}$ the fluxes are almost the same. Most of the energy is deposited above $175 \mathrm{~km}$, i.e., the downward heat flux at $175 \mathrm{~km}$ is down by at least an order of magnitude.

In Figure 5 we show the energy loss rates. Again, the rate at the higher altitudes is greatly elevated on 24 April 1983 compared to 23 April 1983. The values integrated between 175 and $550 \mathrm{~km}$ are $0.5 \mathrm{ergs} / \mathrm{cm}^{2}-\mathrm{s}$ and $0.2 \mathrm{ergs} / \mathrm{cm}^{2}-\mathrm{s}$, respectively. However, these values could be more subject to systematic errors than the heat flux. Such errors could arise from the neutral density in the model, the ratio of molecular to atomic ions in the data reduction, or the $T_{\infty}$. The first two are most likely in opposite directions; the third is small. Overall, we estimate the uncertainty to be no worse than a factor of two and probably to be better than that.

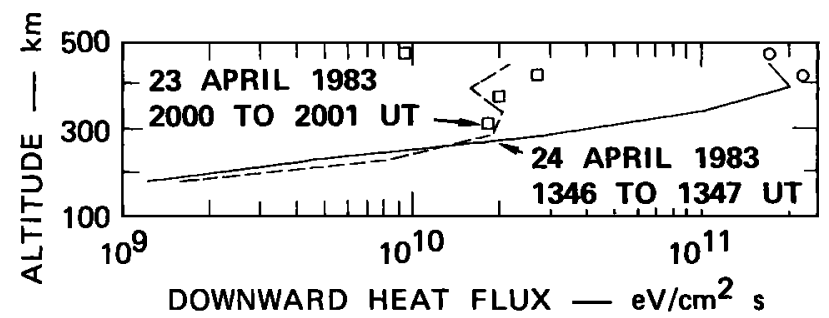

Fig. 4. Downward electron heat fluxes. The profiles are based on temperature gradients calculated from a fitted function. The individual points are based on the Te values.

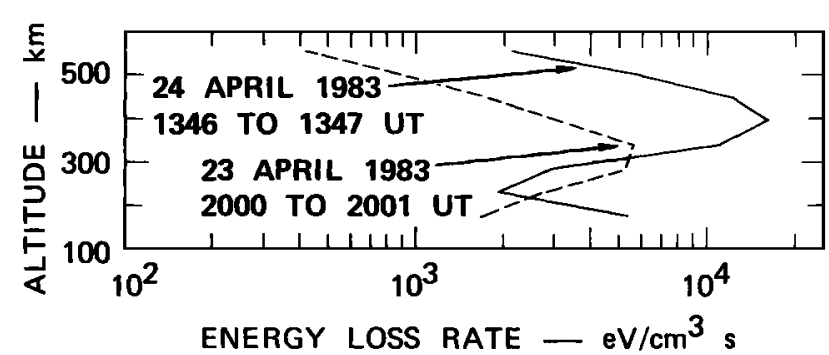

Fig. 5. Electron energy loss rates. The $\mathrm{T}_{\infty}$ used was $1250 \mathrm{~K}$ on 23 April 1983 and $1300 \mathrm{~K}$ on 24 April 1983.

$-$

As expected, the height integrated energy loss rates (equal to the net energy input rates) are larger than the heat fluxes. The difference includes energy deposition from solar EUV and particle precipitation. The heat flux appears to provide a very significant contribution to the total energy input on 24 April 1983, but only a minor one on 23 April 1983.

Finally, the total energy input to the F-region electrons is very large on both days, but especially so on 24 April 1983. Most of this energy will end up in the neutrals, where it will create large perturbations. For instance, we calculate $41 \mathrm{kR}$ of 6300-A emission because of thermal excitation. Other perturbations might occur in the neutral temperature, composition, and winds.

\section{Summary}

In the daytime very high latitude ionosphere, we show two examples of $\mathrm{Te}$ profiles with greatly elevated values above $300 \mathrm{~km}$, reaching $6000 \mathrm{~K}$ at $500 \mathrm{~km}$. The heated electrons occur in a region $150 \mathrm{~km}$ wide located at the convection reversal in the afternoon convection cell. This large temperature increase results from energy input from particle precipitation and from downward heat flux. We determine that the latter at $450 \mathrm{~km}$ is $0.3 \mathrm{ergs} / \mathrm{cm}^{2}-\mathrm{s}$ and the total energy absorbed by electrons between 175 and $550 \mathrm{~km}$ is approximately $0.5 \mathrm{erg} / \mathrm{cm}^{2}-\mathrm{s}$. This significant energy input is passed on mostly to the neutrals thereby also causing major perturbations in the neutral atmosphere.

Acknowledgments. We thank the many SRI personnel who have helped make this research possible. In particular, we appreciate the considerable efforts of Carol Leger and Sam Todd. The Sondrestrom radar is operated by SRI International under NSF cooperative agreement ATM8121671. This research has been supported in part by the above, by AFOSR contract F49620-83-K-0005, and by CNRS.

\section{References}

Bauer, P., P. Waldteufel, and D. Alcayde, Diurnal variations of the atomic oxygen density and temperature determined from incoherent scatter measurements in the ionospheric F region, J. Geophys. Res., 75, 4825-4832, 1970.

Brace, L. H., R. F. Theis, and W. R. Hoegy, A global view of F-region electron density and temperature at solar maximum, Geophys. Res. Lett., 9, 989-992, 1982.

Fontheim, E. G., R. S. B. Ong, R. G. Roble, H. G. Mayr, M. 
J. Baron, W. H. Hoegy, V. B. Wickwar, R. R. Vondrak, and J. A. Ionson, Effect of anomalous transport coefficients on the thermal structure of the storm time auroral ionosphere, J. Geophys. Res., 83, 4831-4836, 1978.

Jacchia, L. G., Revised static models of the thermosphere and exosphere with empirical temperature profiles, Smithson. Astrophys. Obs. Rep., 332, 1971.

Kozyra, J. U., T. E. Cravens, A. F. Nagy, M. O. Chandler, L. H. Brace, N. C. Maynard, D. W. Slater, B. A. Emery, and S. D. Shawhan, Characteristics of a stable auroral red arc event, Geophys. Res. Lett., 9, 973-976, 1982.

Reiff, P. H., J. L. Burch, and R. A. Heelis, Dayside auroral arcs and convection, Geophys. Res. Lett., 5, 391-394, 1978.

Schunk, R. W., "The Terrestrial Ionosphere" in SolarTerrestrial Physics, edited by R. L. Carovillano and J. M. Forbes, pp. 609-676, D. Reidel, Boston, MA, 1983.

Schunk, R. W., and A. F. Nagy, Electron temperatures in the $F$ region of the ionosphere: Theory and observations,
Rev. Geophys. and Space Phys., 16, 355-399, 1978.

Titheridge, J. E., Ionospheric heating beneath the magnetospheric cleft, J. Geophys. Res., 81, 3221-3226, 1976.

Wickwar, V. B., J. D. Kelly, O. de la Beaujardière, C. A. Leger, F. Steenstrup, and C. H. Dawson, Sondrestrom overview, Geophys. Res. Lett., this issue, 1984.

Wickwar, V. B. and W. Kofman, Dayside red auroras at very high latitudes: The importance of thermal excitation, Geophys. Res. Lett., this issue, 1984.

W. Kofman, CEPHAG (LA346), B. P. 46, 38402 St. Martin d'Hères, France.

V. B. Wickwar, Radio Physics Laboratory, SRI International, 333 Ravenswood Avenue, Menlo Park, CA 94025.

(Received June 28, 1984; accepted July 16, 1984.) 